\title{
Fortalecimiento del trámite de la conciliación como mecanismo para descongestionar los tribunales civiles de justicia
}

\author{
José Alberto Allende Pérez de Arce*
}

\section{RESUMEN}

En el presente trabajo propondremos el fortalecimiento del trámite de la conciliación que considera el Código de Procedimiento Civil como mecanismo para descongestionar los tribunales civiles de justicia, inspirados en la corriente internacional que desde hace algunas décadas impulsa el uso de mecanismos alternativos de resolución de controversias para lograr sistemas civiles de justicia más eficientes y eficaces. Para lograrlo se propone la adopción de varias medidas a corto plazo, sin necesidad de una reforma legal.

Conciliación - solución de controversias - descongestión de tribunales

\section{Strengthening the Conciliation Stage as a mechanism to decongest the Civil Courts of Justice}

\begin{abstract}
In this work will be analysed the strengthen of the judicial conciliation regulated in the Civil Procedure Code as a mechanism to reduce the case load of civil courts of justice, inspired in the international tendency that for some decades has encouraged the use of alternative dispute resolution methods to achieve more efficient civil procedural systems. Different steps are proposed to be taken in the short term, without the need for a legal reform.
\end{abstract}

Conciliation - dispute resolution - case load reduction

* Licenciado en Ciencias Jurídicas, Universidad de los Andes, Chile. Magíster en Derecho (LLM), University College London, Inglaterra.

Artículo recibido el 26.2.2018 y aceptado para su publicación en este número el 18.1.2019. 


\section{INTRODUCCIÓN Y CONTEXTO DEL ASUNTO}

$\mathrm{P}$ ara nadie es un misterio que el sistema procesal civil chileno no da abasto para conocer de manera eficiente de todos los asuntos que se promueven ante los tribunales de justicia ${ }^{1}$. Dos son los factores principales que explican esta situación: por un lado, el alto número de causas que ingresan a los tribunales civiles y, por el otro, la ausencia de un procedimiento civil acorde a nuestros tiempos ${ }^{2}$.

Las cifras son asombrosas. Solo el 2016 ingresaron 2.220.401 demandas a los tribunales civiles del país ${ }^{3}$, lo que implica un aumento de más de $20 \%$ en comparación con el número de ingresos del $2010^{4}$. Si a eso sumamos que nuestro procedimiento civil rige desde 1902, y que hoy mantiene intactas ciertas características propias de esa época, no debe sorprendernos el que nuestra justicia no logre actuar como se espera que lo haga. La existencia de un proceso eminentemente escrito ${ }^{5}$, la presencia de anticuados formalismos $^{6}$, la falta de mecanismos alternativos de solución de controversias ${ }^{7}$, son algunos de los resabios históricos que tienen a nuestra justicia civil al borde del colapso. Es demostrativo de lo anterior el que un juicio ordinario al año 2009 tardaba en promedio 821 días (más de dos años) en terminar por sentencia definitiva de primera instancia ${ }^{8}$, mientras que en los juicios sumarios el promedio de duración de los juicios -que son por esencia breves- es de 226,7 días (al 2009)9.

Diversas propuestas han surgido para terminar con la congestión de los tribunales civiles, y lograr una justicia más eficaz ${ }^{10}$. De hecho hoy se encuentra estancado en el Congreso un proyecto de reforma al Código de Procedimiento Civil (en adelante el "Proyecto de Ley" y el "CPC", respectivamente) cuyo objeto es modernizar el sistema judicial civil ${ }^{11}$. Nadie sabe si dicho proyecto verá alguna vez la luz, por lo que los problemas que pretende corregir están lejos de terminar. Peor aún, el 2015 entró en vigencia la Ley N $\mathrm{N}^{0}$ 20.886, que instituyó el denominado sistema de "Tramitación Digital de los Procedimientos Judiciales”, una ley parche que vino a solucionar, provisoriamente,

${ }^{1}$ Larroucau, 2017, p. 196.

2 Maturana y Rivero, 2012, p. 20.

${ }^{3}$ http://www.ine.cl/estadisticas/sociales/justicia

${ }^{4}$ http://www.ine.cl/estadisticas/sociales/justicia

${ }^{5}$ Romero, 2012, p. 179.

${ }^{6}$ En la interrogación de testigos, por ejemplo, los abogados no están facultados para dirigir directamente preguntas al testigo, sino que todas deben ser conducidas por medio del receptor judicial.

${ }^{7}$ Maturana y Rivero, 2012, p. 31.

${ }^{8}$ Centro de Estudios de Justicia de las Américas, 2011, p. 22. Este informe fue elaborado por encargo del Ministerio de Justicia al Centro de Estudios de Justicia de las Américas (CEJA), en el contexto del proyecto de reforma al CPC presentado al Congreso el 2009.

${ }^{9}$ Ibid., p. 26.

${ }^{10}$ Para un análisis más profundo acerca de los distintos cambios que se han propuesto respecto del proceso civil ver las distintas obras contenidas en Aguirrezabal (ed.), 2012.

11 Proyecto de Ley de Nuevo Código Procesal Civil, despachado el 12 de marzo de 2012 por medio del Mensaje $\mathrm{N}^{\circ}$ 432-359. 
algunas de las carencias del proceso en comento. Lamentablemente dicha ley tuvo como efecto secundario suprimir -al menos en apariencia- la urgencia del Proyecto de Ley, quedando pendiente todavía una reforma substancial al proceso civil que corrija los problemas de los que padece.

La situación anterior es la que motiva la elaboración del presente trabajo. Creemos que el fortalecimiento de la figura de la conciliación ${ }^{12}$ es clave para lograr un rápido y positivo impacto en la carga de trabajo de los tribunales civiles de justicia. Ello basado en las siguientes dos razones: en primer lugar, esta estrategia ya ha sido implementada de manera exitosa en países como Inglaterra y Estados Unidos, lo que permite aprovechar dicha experiencia y no partir desde cero. En segundo lugar, la conciliación ya se encuentra regulada en nuestro ordenamiento procesal civil, existiendo los mecanismos suficientes para que su correcta implementación y fortalecimiento no necesiten de una reforma legal previa. En el presente trabajo abordaremos ambos argumentos, y nos haremos cargo de las críticas que pudieran existir respecto del fortalecimiento de la figura de la conciliación.

\section{ORdenAmientos QUE YA HAN UTILIZAdo LA CONCILIACióN COMO MECANISMO DE DESCONGESTIÓN DE LOS TRIBUNALES CIVILES DE JUSTICIA}

Las jurisdicciones del mundo anglosajón han sido pioneras en el fortalecimiento de los mecanismos alternativos de solución de controversias. En Inglaterra, por ejemplo, hace algunas décadas se reformó de forma sustancial el sistema procesal civil, siendo el fortalecimiento de la conciliación uno de los pilares fundamentales de la reforma ${ }^{13}$. Con ese propósito se impuso a los tribunales la obligación de asistir a las partes en la búsqueda de un acuerdo ${ }^{14}$ y de recomendarles la solución del conflicto por medio de un mecanismo distinto del litigio ${ }^{15}$, e incluso se los facultó para que, bajo ciertas circunstancias, apliquen sanciones económicas a aquella parte que habiendo recibido una oferta válida de arreglo la rechaza, y luego obtiene en el juicio un resultado menos favorable que la oferta que rechazó ${ }^{16}$.

En Estados Unidos, por su parte, las Federal Rules of Civil Procedure-que regulan el procedimiento civil en las Cortes civiles de dicho país- también incluyen algunas disposiciones destinadas a incentivar, e incluso forzar, la búsqueda de un acuerdo entre las partes. En ese sentido, y previo al inicio del juicio, se faculta al tribunal para que cite

\footnotetext{
${ }^{12}$ Entiéndase conciliación como el arreglo alcanzado entre las partes en el marco de un juicio, con la intervención del juez como amigable componedor, Corral, 2013.

13 Para un estudio más acabado acerca de la reforma en comento ver Woolf, 1995.

${ }^{14}$ Norma número 1.4.2.f.

15 Norma número 1.4.2.e.

${ }^{16}$ Norma número 36.17 CPR.
} 
a las partes implicadas a una conferencia, para facilitar un posible arreglo ${ }^{17}$. Asimismo considera una regla que sanciona a la parte que rechaza una oferta, en caso de que con la sentencia no haya obtenido más de lo que se le ofrecía en la oferta que rechazó ${ }^{18}$.

Finalmente hacemos mención a los Principios ALI/UNIDROIT del Proceso Civil Transnacional $^{19}$, los que recomiendan que el tribunal asuma un rol activo en la búsqueda de acuerdos, y que tenga la facultad de sancionar a las partes que no se comprometan fehacientemente con dicho propósito ${ }^{20}$.

Lo dicho anteriormente demuestra que el fortalecimiento de la solución alternativa de controversias, y entre ellas la conciliación, es una estrategia que lleva varios años siendo aplicada en distintas jurisdicciones. Nótese que en Inglaterra en 1998 (un año antes de que la reforma procesal civil entrara en vigor) se iniciaron 114.984 casos civiles. El 2003, en tanto, se iniciaron tan solo 14.191 causas, lo que implicó una reducción del $800 \%$ de $\operatorname{casos}^{21}$. Ello demuestra la eficacia de los mecanismos alternativos de solución de controversias para descongestionar los tribunales de justicia.

\section{Situdución en Chile}

El segundo argumento por el que sugerimos que se fortalezca la conciliación como medida para descongestionar los tribunales civiles se refiere a que en Chile dicha figura ya se encuentra cabalmente regulada en materia civil, por lo que su debida implementación no requiere de una reforma legal previa.

\section{Contexto histórico en materia procesal civil}

El primer antecedente del trámite de conciliación en nuestra historia republicana se encuentra contenido en la Constitución "Moralista” de 1823, que en su Título XV, denominado "de los Jueces de Conciliación”, imponía a las partes la obligación de intentar una solución amistosa del litigio antes de su inicio. En ese sentido el artículo 167 disponía que "[n]inguno puede presentarse a los tribunales ordinarios con demanda judicial, sin

${ }_{17}^{17}$ Regla 16.a.5.
${ }_{18}$ Regla 68.d.
${ }^{19}$ Disponible en http://www.unidroit.org/instruments/transnational-civil-procedure, visitado el 4 de

${ }^{19}$ Disponible en http://www.unidroit.org/instruments/transnational-civil-procedure, visitado el 4 de
mbre 2017. La versión en español se encuentra disponible en https://www.unidroit.org/english/principles/

${ }^{20}$ En la norma número 24.1 se señala expresamente que "[E]l Tribunal, respetando la libertad de las partes de proseguir el litigio, deberá incentivar el acuerdo entre estas, cuando sea razonablemente posible". Luego la norma 24.2 dispone que "[E]l tribunal deberá favorecer la participación de las partes en procedimientos alternativos de resolución de controversias durante cualquier etapa del procedimiento". Finalmente la norma 24.3 ordena a las partes "cooperar con cualquier esfuerzo conciliatorio razonable", para luego conceder al Tribunal la facultad de "ajustar la condena en costas para reflejar la irrazonable falta de cooperación, o la participación de mala fe en los esfuerzos conciliatorios”.

${ }^{21}$ Roberts y Palmer, 2005, p. 69. 
haber ocurrido a los de conciliación"; el artículo 168 por su parte que debía "llamarse a conciliación toda demanda civil y las criminales que admitan transacción sin perjuicio de la causa pública. Pueden llamarse también las eclesiásticas sobre derechos personales y acciones civiles"; el artículo 169 en tanto, que "[e]l ministerio de los conciliadores, es oír la solicitud de las partes con los justificativos que basten para dar alguna noción del asunto y excitar o proponer medios de conciliación, instruyéndola de sus derechos”. En igual sentido, la Constitución de 1828 también previó la existencia de "juzgados de paz”, cuyo propósito era "conciliar los pleitos en la forma que señale una ley especial”.

No obstante lo anterior, el CPC actual, al entrar en vigencia en 1903, no contenía ninguna mención al trámite de conciliación, situación que se mantuvo hasta 1944 , cuando por medio de la Ley $\mathrm{N}^{\circ} 7.760$ se incluyó dicho trámite como facultativo del tribunal $^{22}$. El cambio pretendía lograr un sistema de justicia civil más rápido y eficaz ${ }^{23}$. No obstante el cambio, el trámite potestativo de conciliación no produjo los efectos pretendidos con la reforma, lo que motivó a que el mismo se transformara en obligatorio - en la mayoría de los procedimientos civiles- por medio de la dictación de la Ley No 19.934 de 1994. Según se desprende del mensaje de la ley en comento, el propósito de esta segunda reforma fue disminuir la carga de trabajo de los tribunales:

“[D]entro del espíritu de las reformas que se aspiran a introducir a nuestro sistema judicial se deben consagrar preceptos que den mayor rapidez a la tramitación de las causas y que pongan término a las mismas en forma prudencial. La conciliación es un instrumento procesal que aplicado en la etapa anterior a la demanda propiamente tal podrá contribuir a solucionar contiendas que a veces suelen prolongarse innecesariamente" 24 .

Es más, con el ánimo de evitar el gasto innecesario de recursos la moción parlamentaria proponía que el trámite de conciliación tuviera lugar antes de iniciarse el proceso. El objetivo era evitar que un conflicto susceptible de ser solucionado de forma amistosa por las partes siguiera adelante, consumiendo tiempo y recursos de los tribunales civi$\operatorname{les}^{25}$. Si bien la pretensión de una conciliación prejudicial fue finalmente rechazada por

${ }^{22}$ Con la reforma en comento se incluyó el siguiente texto: "En todo juicio civil y con excepción de los juicios o procedimientos especiales de que tratan los Títulos IV, VI y XVIII, del Libro II, el juez podrá en cualquier estado de la causa llamar a las partes a conciliación y proponer bases de arreglo".

${ }^{23}$ Como señala Tapia, "nuestro Código de Procedimiento Civil, promulgado por Ley No 1552 de 28 de agosto de 1902, era criticado por parte considerable de la doctrina nacional, que estimaba que era "menester ponerle a tono con la época en que vivimos, en forma que la justicia que a través de él se administre pueda ser rápida, que es condición indispensable para que sea, también, eficaz”, en TAPIA, 1944, p. 295.

${ }^{24}$ Historia Fidedigna de la Ley No 19.934, 1994, páginas 4 y 5, moción parlamentaria, primer trámite constitucional.

${ }^{25}$ Historia Fidedigna de la Ley No 19.934 , 1994, páginas 7 y siguientes, primer trámite constitucional, informe Comisión de Constitución, Legislación y Justicia. 
el Congreso ${ }^{26}$, el resto de la ley fue aprobada, y se convirtió en la regulación que hoy contiene nuestro CPC en materia de conciliación.

\section{La regulación de la conciliación en el procedimiento civil chileno actual ${ }^{27}$}

El trámite de conciliación en el juicio ordinario se encuentra regulado en los artículos 262 y siguientes del CPC. El artículo 262 dispone que en todo juicio civil en que sea admisible la transacción (exceptuados ciertos procedimientos especiales, tales como los juicios ejecutivos, los juicios de declaración del derecho legal de retención, en los procedimientos de citación a evicción y en los juicios de hacienda), las partes deberán ser citadas por el Tribunal a una audiencia de conciliación, que tendrá lugar una vez agotada la etapa de discusión. En dicha audiencia el Tribunal obrará como amigable componedor y propondrá a las partes bases de arreglo, labor que no lo inhabilitará para seguir conociendo del asunto en caso de fallar la conciliación (artículo 263 del CPC).

Ese es el contexto general. Sumado a lo anterior, el CPC establece que las partes pueden concurrir por sí o representadas por apoderado, sin perjuicio de que el Tribunal pueda exigir la comparecencia personal de la parte (artículo 264); que en caso de pluralidad de partes la conciliación solo afecta a aquellas partes que la suscriban (artículo 264); que la audiencia puede suspenderse a solicitud de parte en aras de explorar el eventual acuerdo (artículo 265); que el Tribunal puede de oficio ordenar la realización de diligencias probatorias que faciliten el arreglo (artículo 266); que en caso de alcanzarse un acuerdo entre las partes este deberá constar en un acta, la que se estimará como sentencia ejecutoriada para todos los efectos legales (artículo 267); y que en caso de fallar la conciliación o no efectuarse el comparendo, se dará curso progresivo al procedimiento (artículo 268). En caso de fallar la audiencia de conciliación en comento, el tribunal se encuentra facultado para citar a las partes a una nueva audiencia, si estima que hay posibilidades de lograr un arreglo (artículo 262).

Para el juicio de menor cuantía el artículo 698 del CPC dispone que el juez deberá citar a las partes a una "audiencia de conciliación para un día no anterior al tercero ni posterior al décimo contado desde la fecha de notificación de la resolución”, mientras que el artículo 711 del CPC dispone que en los juicios de mínima cuantía, en la misma

26 Según se desprende de la Historia de la Ley $\mathrm{N}^{\circ} 19.934$, 1994, dentro de las razones por las que se rechazó la conciliación prejudicial destacan el que el tribunal estaría en mejor posición de conocer los hechos una vez que se diera término al período de discusión, luego de haber oído a ambas partes. Asimismo se prefirió evitar conflictos con el principio procesal de que la litis queda trabada, y los hechos objeto del proceso fijados, con la contestación de la demanda.

${ }^{27}$ Si bien en este trabajo solo nos referimos al trámite de la conciliación contenido en el CPC, se hace presente que esta institución ya se ha visto fortalecida en otros procedimientos contenciosos civiles de nuestro ordenamiento, como es el procedimiento colectivo regulado en la Ley de Protección al Consumidor (Ley $\mathrm{N}^{\circ} 19.496$ de 1997, reformada en este tema por la Ley $\mathrm{N}^{\circ} 21.081$ de 2018); el procedimiento regulado en el artículo 19 de la Ley General de Urbanismo y Construcciones; y el trámite de conciliación del procedimiento regulado en los artículos 132 y 132 bis del Código Tributario. 
audiencia en la que el demandado contesta la demanda y opone sus excepciones, el tribunal "llamará a las partes a avenimiento" 28 .

Finalmente el artículo 795 del CPC enumera dentro de los trámites o diligencias esenciales en la primera o en la única instancia en los juicios de mayor o de menor cuantía y en los juicios especiales (salvo aquellos expresamente excluidos), el llamado a las partes a conciliación. En los juicios de mínima cuantía la diligencia de conciliación también es considerada esencial, según el artículo 789 del CPC.

De lo anterior queda en evidencia que, al menos en el papel, la conciliación juega un rol importante en el desenvolvimiento del proceso civil. Lamentablemente, según veremos a continuación, los esfuerzos del legislador no han estado en sintonía con la ejecución que han recibido estas normas en la práctica.

\section{El trámite de conciliación del CPC en la práctica}

Es un hecho sabido que el trámite de la conciliación es generalmente enfrentado por el tribunal y por las partes sin la seriedad debida, y con el único propósito de cumplir con la formalidad. En otras palabras, lo normal es que la realización de este trámite no tiene por objeto lograr el arreglo entre las partes respecto de la cuestión disputada. A continuación relataremos brevemente la forma en que normalmente se lleva a cabo el trámite de la conciliación.

Una vez terminada la etapa de discusión en el juicio, las partes son citadas por el tribunal a una audiencia fijada especialmente para tal efecto, a realizarse en un determinado día a partir de la notificación por cédula de la resolución que la decretó. El día fijado en la resolución las partes son llamadas a viva voz por un funcionario del tribunal, quien en caso de que ambas asistan, las invita a ingresar a la sala de audiencias, para posteriormente preguntarles si es que existen o no posibilidades de arreglo. En caso de que la respuesta sea afirmativa, serán las partes las que llevarán adelante las conversaciones para afinar el potencial arreglo, y posiblemente solicitarán la suspensión de la audiencia para discutir con calma el cierre de la disputa. Es decir, el Tribunal queda en la práctica al margen del proceso conciliatorio. En caso de que la respuesta sea negativa -y que no exista posibilidad de arreglo entre las partes- el actuario procede a redactar un acta "tipo", dejando constancia de que el arreglo no fue alcanzado ("llamadas las partes a conciliación, esta no se produce"). En caso de que solo una de las partes asista, la audiencia se lleva a cabo igualmente, variando solamente el contenido del acta redactada por el actuario, quien deberá dejar constancia tanto de la ausencia de una de las partes como del fracaso de la conciliación. Finalmente, en caso de que ninguna de las partes asista a la diligencia, la audiencia no se realiza, debiendo el tribunal certificar dicha circunstancia y luego dar curso progresivo al juicio.

${ }^{28}$ No compartimos la terminología utilizada por el CPC en este artículo, porque el hecho de que las tratativas de arreglo se hagan en presencia del tribunal convierte el resultado de las mismas en una conciliación y no en un avenimiento. 
De lo anterior queda en evidencia que la audiencia de conciliación no es más que el cumplimiento de una mera formalidad en el juicio. Si bien las partes son citadas a conciliar, en la práctica el Tribunal no oficia como amigable componedor, ni propone bases de arreglo. Tampoco vierte opiniones que puedan facilitar el avenimiento, y mucho menos decreta diligencias probatorias con ese mismo fin. La realidad es que el juez rara vez interviene personalmente en las audiencias de conciliación (a pesar del mandato legal expreso que tiene de hacerlo), y el actuario que lo hace en su representación por lo general no ha revisado los antecedentes del caso.

La situación antes descrita se encuentra respaldada con cifras oficiales que maneja el Poder Judicial. Así como lo reflejan las estadísticas del INE, de las 2.220.401 causas civiles que el 2016 ingresaron a los tribunales civiles, tan solo 1.477 terminaron por conciliación (el 0,06\%), mientras que 83.578 lo hicieron por sentencia definitiva ${ }^{29}$. El resto de las causas que terminaron lo hicieron por otras razones. Si se distingue por tipo de procedimiento tenemos que al 2009 el total de juicios ordinarios iniciados fue de 12.278, terminando por conciliación solo 6 de ellos (el 0,05\%) ${ }^{30}$. El mismo 2009 se iniciaron 7.888 juicios sumarios, de estos, 92 terminaron en conciliación (el 1,17\%) Las cifras hablan por sí solas. El trámite de la conciliación en nuestro país se ha convertido en una mera formalidad, y no produce efectos en la práctica.

\section{Consecuencias}

El que el número de litigios que termina en una etapa procesal temprana con el acuerdo entre las partes sea marginal respecto del número de causas que ingresan y del número de sentencias definitivas que se dictan, acarrea varias consecuencias negativas para el sistema.

En primer lugar, la realización de audiencias de conciliación implica que el Poder Judicial, y por tanto el Estado, destina día a día importantes recursos a nivel nacional solo para dar cumplimiento a esta formalidad. Nótese que el tribunal, para cada audiencia de conciliación que realiza, debe poner a disposición de las partes a un funcionario, un escritorio y un computador, los que permanecerán ocupados durante al menos treinta minutos, que es lo que estimamos dura en promedio este trámite desde el llamado a viva voz a las partes hasta la firma del acta por parte de los asistentes.

${ }^{29}$ Información obtenida del Instituto Nacional de Estadísticas (INE), http://www.ine.cl/estadisticas/ sociales/justicia. Se hace presente que no obstante ser estas cifras oficiales, existe un antecedente que puede llevar a confusión. No está claro, pero se asume, que la estadística se refiere al número de causas que ingresaron al sistema el 2016 y las que salieron del sistema ese mismo 2016, sin que necesariamente sean las mismas causas las que entran y salen ese año. Atendida la duración promedio de los juicios civiles, no es razonable pensar que las más de 83 mil sentencias definitivas dictadas lo fueron sobre causas ingresadas ese mismo año. No obstante lo anterior, utilizaremos las cifras del INE por ser oficiales, y por reflejar la realidad que se pretende transmitir con este trabajo.

${ }^{30}$ Centro de Estudios de Justicia de las Américas, 2011, p. 23.

31 Ibid., p. 26. 
En segundo lugar las partes del juicio también deben incurrir en importantes gastos para que se lleve a cabo la formalidad en comento. Tener a un abogado a disposición de la causa durante al menos una hora (considerando la duración de la audiencia, desplazamiento al tribunal, etc.), tener que notificar por cédula la realización de la diligencia por medio de receptor judicial, son costos no menores que deben ser asumidos por las partes.

En tercer lugar, la realización de audiencias de conciliación no solo implica un desperdicio de recursos, sino que también constituye una fuente de demora para la tramitación de las otras causas de las que conoce el tribunal. Es decir, la formalidad de la conciliación no solo demora a la causa en la que se lleva a cabo la audiencia (la que se ve suspendida mientras se dicta y notifica la resolución que cita a la audiencia. Ello sin contar las eventuales suspensiones de la audiencia, los recursos que se interpongan en contra de la resolución, las eventuales nulidades que se promuevan, etc.), sino que también a todas aquellas otras causas que se tramitan ante ese mismo tribunal, que se ven demoradas en su tramitación por la destinación de importantes recursos para la realización de la audiencia.

La situación anterior es lamentable. No podemos entender que tengamos funcionando un costoso sistema que no cumple con el objetivo para el que fue creado. Creemos que existen solo dos alternativas posibles (si se quiere racionalizar el sistema): o el sistema actual se perfecciona o se elimina, pero no podemos tener al Estado despilfarrando recursos en el cumplimiento de una formalidad, mientras nos farreamos la posibilidad de beneficiarnos de las ventajas que ofrece un sistema de conciliación judicial bien implementado.

\section{Medidas Para Fortalecer la Figura de la CONCILIACión EN EL PROCESO CIVIL CHILENO}

Estando clara la importancia de que exista un sistema eficiente que promueva la conciliación entre las partes, a continuación realizaremos algunas propuestas que podrían ser implementadas en nuestro ordenamiento procesal civil.

\section{Cambios en el Poder Judicial}

Si bien es evidente que para fortalecer la conciliación tienen que existir cambios a nivel de los tribunales, estos cambios son menores. Como se ha expuesto, hoy nuestro CPC contiene una detallada regulación del trámite de la conciliación, que va desde la dictación de la resolución citando a las partes, hasta el levantamiento del acta respectiva. De ello se sigue que para fortalecer la figura de la conciliación no sería necesario introducir cambios substanciales en el procedimiento, sino que dichos cambios debieran concentrarse en la forma en que el Tribunal se involucra en la práctica de la diligencia.

El cambio que consideramos más importante por parte del Poder Judicial será que el juez (o el funcionario designado para tal efecto) llegue preparado a la audiencia, lo que implica haber revisado en detalle no solo la discusión de las partes, sino que también los 
antecedentes probatorios que a esas alturas consten en el proceso. No hay forma alguna de que la audiencia sea provechosa si aquel llamado a oficiar de amigable componedor y a proponer bases de arreglo a las partes si ni siquiera se ha leído el expediente.

Sabemos que la implementación de este cambio puede ser complicada en un principio atendida la carga de trabajo de los tribunales. Sin embargo este obstáculo no es insuperable, sino todo lo contrario. En primer lugar, si se fortalece correctamente la conciliación el número de causas en el tribunal, y por tanto el trabajo de sus funcionarios, debiera reducirse considerablemente, permitiendo más tiempo a dichos funcionarios para preparar las audiencias en la forma propuesta. Es un círculo virtuoso: menos trabajo, y de mejor calidad. Por otra parte, se debe tener en cuenta que llegado el momento de dictarse la sentencia de la causa, el juez (o el funcionario designado para tal efecto) igual deberá estudiar minuciosamente el expediente -ahora con todos los antecedentes agregados durante largos años de tramitación-, por lo que en ningún caso la preparación de la audiencia puede considerarse una pérdida de tiempo en aquellos casos en los que no se alcance un arreglo entre las partes y el juicio deba proseguir con su tramitación ${ }^{32}$.

El segundo cambio que sugerimos implementar, que debe ser en conjunto con el anteriormente expuesto, será que cada tribunal destine parte de su personal exclusivamente a preparar la audiencia de conciliación, debiendo determinarse el número de funcionarios según la carga de trabajo del tribunal ${ }^{33}$. Así, en cada juzgado existirían oficiales de conciliación, debidamente capacitados, cuya única labor sería estudiar los expedientes y proponer a las partes bases de arreglo en la etapa de conciliación ${ }^{34}$.

Relacionado con lo anterior, el tercer cambio que proponemos es que tanto los jueces como los funcionarios que eventualmente se aboquen a la labor conciliatoria, deban capacitarse en el arte de la mediación, para ello creemos necesario que la Academia Judicial disponga de los mecanismos adecuados para hacerlo. Si bien tanto la conciliación como la sentencia tienen por objeto resolver disputas entre partes, las habilidades que se requieren para una y otra son distintas. Por ejemplo al explorar y proponer bases de arreglo, el juez debe ser cuidadoso de no emitir prejuzgamientos ${ }^{35}$, de no generar expectativas falsas o inadecuadas entre las partes, de no delatar una preferencia o debilidad que pueda ser aprovechada a futuro por alguna de las partes en caso de fallar la conciliación, entre

${ }^{32}$ Una posibilidad para motivar que los jueces se tomen en serio esta diligencia podría ser que el descuido de la misma sea denunciado por las partes por medio de la queja disciplinaria regulada en el artículo 535 y 536 del COT. Esta opción, sin embargo, debe ser considerada con cuidado, toda vez que si la conciliación fracasa, será ese mismo juez el que seguirá conociendo del asunto, lo que podría generar algún grado de animadversión de este en contra de la parte que se quejó.

33 Esta idea no es nueva, sino que se aplica a diario en los tribunales civiles respecto de otros asuntos. Es común encontrar actuarios dedicados únicamente a tramitar excepciones en juicios ejecutivos; otros que se dedican a preparar sentencias; otros que proveen demandas nuevas; entre otros casos.

${ }^{34}$ Coinciden con esta idea Núñez y Larroucau, quienes proponen que sea el secretario de cada Juzgado Civil quien asuma la labor de proponer las bases de acuerdo para cada caso. Núñez O., Raúl y LARROUCAU T., Jorge (2018), p. 696.

35 Sin perjuicio de que el artículo 263 del CPC expresamente señala que las opiniones que emita en la instancia conciliatoria no inhabilitan al juez para seguir conociendo de la causa. 
otras exigencias. Hay que asumir que fallar una causa no es lo mismo que intentar el arreglo de la misma -requieren habilidades distintas- y por tanto la capacitación en el rubro es imperiosa ${ }^{36}$. Como lo exponen Palomo y Matamala, el fortalecimiento de los poderes del tribunal en la etapa de conciliación no puede perder de vista el real sentido de la administración de justicia, por muy loables que sean los objetivos que se tuvieron en mente al momento de reconocerle dichas potestades al órgano jurisdiccional ${ }^{37}$.

Los cambios anteriores son perfectamente posibles de llevarse a cabo en el marco de la institucionalidad vigente. Como sabemos, la Corte Suprema tiene la superintendencia directiva, correccional y económica respecto de casi todos los tribunales de la República, incluidos los juzgados civiles ${ }^{38}$. El ejercicio de estas facultades, por medio de auto acordados, permitiría a nuestro Máximo Tribunal adoptar las medidas que estime pertinentes para lograr el cambio en comento, aprovechándose de la normativa que ya existe en la materia ${ }^{39}$. Por ejemplo, la Corte Suprema podría establecer pautas claras para la preparación de la audiencia de conciliación; exigir la designación de funcionarios de dedicación exclusiva para el trámite de conciliación, fijar incentivos a los funcionarios que se desenvuelvan correctamente, o sanciones para los que no lo hagan; entre muchas otras opciones que habrán de ser estudiadas en su mérito ${ }^{40}$.

Si bien es cierto que la dictación de auto acordados para regular procedimientos judiciales ha sido blanco de importantes críticas por parte de la doctrina ${ }^{41}$, creemos que las mismas no resultan aplicables al fortalecimiento de la conciliación en la forma que aquí se propone. El principal cuestionamiento que se ha hecho respecto de los auto acordados ha sido que por medio de ellos la Corte Suprema estaría desarrollando una actividad legislativa que naturalmente le está vedada ${ }^{42}$. Pues bien, aun estando de acuerdo con dicha crítica, creemos que la misma no resulta aplicable al caso en estudio,

\footnotetext{
${ }^{36}$ BoK, 1983, p. 570.

37 Palomo y Matamala, 2012, p. 441
}

${ }^{38}$ El artículo 82 inciso primero de la Constitución dispone que "[L]a Corte Suprema tiene la superintendencia directiva, correccional y económica de todos los tribunales de la Nación. Se exceptúan de esta norma el Tribunal Constitucional, el Tribunal Calificador de Elecciones y los tribunales electorales regionales".

${ }^{39}$ El artículo 96 número 4 del Código Orgánico de Tribunales dispone que "[C]orresponde a la Corte Suprema en pleno: $4^{\circ}$ Ejercer las facultades administrativas, disciplinarias y económicas que las leyes le asignan, sin perjuicio de las que les correspondan a las salas en los asuntos de que estén conociendo, en conformidad a los artículos 542 y 543 . En uso de tales facultades, podrá determinar la forma de funcionamiento de los tribunales y demás servicios judiciales, fijando los días y horas de trabajo en atención a las necesidades del servicio", lo que según lo resuelto por el Tribunal Constitucional en la sentencia rol 783-2007, implica que " $[\mathrm{E}] \mathrm{n}$ aspectos de funcionamiento en que el legislador no ha establecido normas o que expresamente la Constitución no la ha reservado a este, el propio órgano judicial puede autorregularse”.

${ }^{40}$ Un caso reciente acerca del ejercicio de facultades administrativas de la Corte Suprema por medio de auto acordados tuvo lugar el 2016, en el que por medio del auto acordado número 37-2016, dicha Corte estableció varias regulaciones destinadas a dar aplicación a la Ley No 20.886, que instituyó el denominado sistema de "Tramitación Digital de los Procedimientos Judiciales".

${ }^{41}$ Una explicación detallada al respecto en LARroucau, 2017.

42 Bordalí, 2016, p. 138. 
toda vez que según ya explicamos, el trámite de la conciliación ya está detalladamente regulado en el CPC, y lo que habría que regular por medio de un auto acordado serían los detalles administrativos para dar aplicación práctica a esas normas, algo que según vimos, sería acorde con la Constitución ${ }^{43}$.

\section{Cambios en las partes y sus abogados}

Las partes del juicio, y especialmente sus abogados, también tienen un rol importante que desempeñar en el fortalecimiento de la figura de la conciliación, ya que los litigantes tienen importante responsabilidad en el fracaso del modelo conciliatorio contenido en el CPC.

Según explicamos, la audiencia de conciliación se lleva a cabo ante el tribunal en presencia de las partes que asisten. No exageramos al afirmar que la labor de la mayoría de los abogados que asisten a las audiencias de conciliación se limita a presenciar el rito descrito previamente. Lo normal es que, consultados por el funcionario de turno si existen o no posibilidades de arreglo, los abogados presentes se limiten a responder de forma negativa, o bien, haciendo una propuesta de conciliación imposible de aceptar para su contraparte. Ahí se acaban los esfuerzos, y luego se procede a levantar el acta dando cuenta del fracaso de la diligencia. Esa actitud necesariamente debe cambiar ${ }^{44}$.

En ese contexto proponemos (o invitamos) a que las partes y sus abogados comiencen a tomar más en serio la diligencia, y a enfrentarla con el real propósito de alcanzar un arreglo. Para ello lo primero será que el abogado analice con su cliente, antes de la audiencia, cuáles son las alternativas razonables para solucionar el conflicto de manera amigable. Que le exponga con transparencia cuáles son a su juicio las fortalezas y debilidades del caso, y transmitirle claramente cuál es el escenario al que se enfrenta en caso de dictarse un fallo adverso (nos referimos no solo al monto de la eventual condena, sino que a los costos en los que deberá incurrir en caso de interponer recursos). Asimismo el abogado debe hacerle saber al cliente los montos que se ahorraría en el caso de llegar a un arreglo (por ejemplo, todos los costos probatorios del caso exceptuados aquellos en los que ya se haya incurrido $)^{45}$.

Sumado a lo anterior, las partes deben entender, y sus abogados asistirlos en ese discernimiento, que el arreglo es muchas veces una mejor alternativa no solo por los dineros y tiempo que se ahorran con él, sino que también, por la relación comercial que mantienen con su contraparte. No son pocos los casos en los que las partes de un juicio han mantenido una relación comercial de larga data, y que la misma se deterioró por uno o varios conflictos puntuales que surgieron en ese contexto. Es obvio que dichos

43 Tribunal Constitucional, sentencia rol 783-2007.

${ }^{44}$ Cappelletti, 1999, p. 296.

45 Un interesante estudio concerniente a los costos de litigación de los asuntos patrimoniales en Chile encontramos en JEQUIER L., Eduardo, 2018, p. 78 (63-113). La información levantada por el estudio en el que se basa la obra citada demuestra los altos costos de litigación asociados a conflictos patrimoniales y, por tanto, las ventajas que representa la conciliación en ese sentido. 
conflictos deben ser resueltos, pero la litigación no parece ser el mecanismo más adecuado para lograrlo. Ello no solo por los altos costos que todo juicio trae aparejados, sino que también por el inevitable desgaste que una disputa en tribunales ocasiona a las partes intervinientes ${ }^{46}$. Este es un factor que en medio de una disputa puede no parecer tan claro para la parte, siendo deber del abogado (y del juez) ilustrarla al respecto.

En tercer lugar hay que tener presente, y eliminar, los conflictos de interés que los abogados pueden tener al enfrentar un proceso conciliatorio en representación de sus clientes. Lamentablemente existen ocasiones en las que los abogados definen su actuar no por aquello que conviene a sus clientes, sino por aquello que resulta más provechoso a sus propios intereses ${ }^{47}$. Lo anterior es especialmente claro cuando se trata de buscar un arreglo a una disputa, y el abogado tiene un acuerdo de honorarios que pueda influir su actitud en dicha instancia ${ }^{48}$. En ese sentido, y sobre todo con clientes de gran envergadura, si el abogado tiene un acuerdo de honorarios que le permite cobrar sus servicios "por hora" (a más horas más honorarios), puede ser que su interés no esté en lograr un buen arreglo para su cliente, sino que en evitar que el juicio termine en una etapa procesal temprana con el fin de seguir cobrando sus honorarios. De la misma forma, y también asociado al conflicto de interés que podrían generar los honorarios, existen casos en los que el pacto de remuneraciones del abogado estará asociado al resultado del juicio, lo que se traduce en que el abogado se quedará con un porcentaje de aquello que recuperó su cliente (abogado demandante), o de aquello que el cliente dejó de pagar (abogado demandado). Nuevamente el actuar del abogado en la conciliación podría quedar condicionado a sus propios intereses económicos, si es que llegar a un arreglo pudiera implicar que sus propios honorarios se vieran reducidos ${ }^{49}$.

La forma de hacerse cargo de esta amenaza - cuyos alcances reales no podemos conocer- es compleja. Los clientes son libres de negociar con sus abogados los honorarios que más convengan a sus intereses, decisión que engloba muchos más aspectos que aquel que estamos analizando. Sin embargo creemos que una manera factible de reducir la tentación de ciertos abogados de definir sus estrategias a partir de sus propios intereses, sería involucrando presencialmente a los clientes en la etapa de conciliación, o al menos en parte de ella. No cabe duda que el abogado tendrá una presión adicional de velar únicamente por los intereses de su cliente si es que él mismo lo acompaña en el trámite de la conciliación.

En cuarto lugar, somos de la opinión que las facultades de derecho a lo largo del país también deben jugar un rol en el fortalecimiento de la conciliación entre las partes. Hoy los estudiantes dedican aproximadamente tres años de sus estudios al derecho procesal,

46 ZuCKERMAN, 2013, punto 1.126.

${ }^{47}$ Luban, 1995, p. 2624. El artículo 3 del Código de Ética del Colegio de Abogados de Santiago dispone que "[E]l abogado debe obrar siempre en el mejor interés de su cliente y anteponer dicho interés al de cualquier otra persona, incluyendo al suyo propio".

48 Galanter y Cahill, 1994, p. 1364.

49 Galanter y Cahill, 1994 , pp. 1376 y 1377. 
y en la gran mayoría de los casos ni siquiera se les menciona que existen mecanismos alternativos de solución de controversias. Lo normal es que los alumnos egresen expertos en plazos, requisitos y formalidades, e incluso algunos logran desarrollar destrezas de litigación. Sin embargo son pocos, por no decir ninguno, aquellos estudiantes que se prepararon para llevar adelante una negociación, para mediar un conflicto entre partes, o incluso para ver un problema con una perspectiva más amplia que el mero texto legal ${ }^{50}$. Es evidente que mientras nuestros abogados sigan siendo educados con esa perspectiva unidimensional, litigiosa, difícilmente tendrán lugar cambios significativos en la materia. Nuevamente conviene mirar hacia el extranjero para entender hacia dónde se mueven las tendencias modernas en materia procesal civil. Desde hace ya varios años que al menos en Estados Unidos e Inglaterra las más importantes facultades de derecho conceden gran atención a la enseñanza de los distintos mecanismos de solución alternativa de controversias ${ }^{51}$.

\section{Mecanismos procesales a disposición de las partes para lograr los cambios propuestos}

En nuestro ordenamiento procesal existen mecanismos a disposición de la partes para lograr que los tribunales civiles lleven a cabo de manera adecuada su labor en la etapa de conciliación.

En primer lugar vemos factible la interposición de una queja disciplinaria en contra del juez en caso de que este no haya cumplido con su labor de amigable componedor, y no haya propuesto a las partes bases de arreglo. En ese sentido el artículo 535 del COT inciso primero mandata a las Cortes de Apelaciones para que mantengan "la disciplina judicial en todo el territorio de su respectiva jurisdicción, velando inmediatamente la conducta ministerial de sus miembros y la de los jueces subalternos y haciéndoles cumplir todos los deberes que las leyes les imponen”, y luego el artículo 536 dispone que dichas Cortes "oirán y despacharán sumariamente y sin forma de juicio las quejas que las partes agraviadas interpusieren contra los jueces de letras por cualesquiera faltas y abusos que cometieren en el ejercicio de sus funciones; y dictarán, con previa audiencia del juez respectivo, las medidas convenientes para poner pronto remedio al mal que motiva la queja”. Debido a que el artículo 263 del CPC le impone al juez civil los deberes de oficiar como amigable componedor y de proponer a las partes bases de arreglo, el incumplimiento de los mismos permite a las partes quejarse de dicho actuar ante la Corte de Apelaciones respectiva, para que esta adopte las medidas convenientes para poner remedio a la conducta que motiva la queja.

${ }^{50}$ BOK, 1983, p. 570.

51 Cappelleti, 1999, p. 291. Así se desprende de la revisión de los sitios web de las distintas universidades: Harvard: http://hls.harvard.edu/dept/opia/what-is-public-interest-law/public-interest-worktypes/alternative-dispute-resolution/; Oxford: https://www.law.ox.ac.uk/research-subject-groups/swiss-recmsprogramme-civil-justice-systems/alternative-dispute-resolution; Stanford: https://law.stanford.edu/courses/ alternative-dispute-resolution-practicum/; University College London: https://www.ucl.ac.uk/laws/study/ llm-master-laws/modules/alternative-dispute-resolution-lawsg094. Esta es solo una muestra. 
Otro mecanismo procesal que pueden utilizar las partes para asegurar el cumplimiento efectivo del procedimiento de conciliación es el recurso de casación en la forma. Dispone el artículo 768 del CPC que " $[E] 1$ recurso de casación en la forma ha de fundarse precisamente en alguna de las causas siguientes: (...) 9 $9^{a}$ : En haberse faltado a algún trámite o diligencia declarados esenciales por la ley o a cualquier otro requisito por cuyo defecto las leyes prevengan expresamente que hay nulidad”. Luego el artículo 795 del mismo cuerpo legal dispone que "[E]n general, son trámites o diligencias esenciales en la primera o en la única instancia en los juicios de mayor o de menor cuantía y en los juicios especiales: $2^{\circ}$. El llamado a las partes a conciliación, en los casos en que corresponda conforme a la ley".

En conclusión, de la lectura armónica de ambas disposiciones se desprende que el recurso en comento es admisible cuando el Tribunal no ha cumplido con el trámite de la conciliación, lo que sin duda constituirá un incentivo adicional para que los Tribunales cumplan de manera correcta su obligación en materia de conciliación. Para los que eventualmente afirmen que lo que exige el artículo 795 antes citado es llamar a conciliación, pero no que el juez obre como amigable componedor y proponga bases de arreglo. No compartimos dicho argumento, porque el trámite de la conciliación se encuentra regulado en detalle en los artículos 262 y siguientes del CPC, por lo que es evidente que a lo que se refiere el artículo 795 es a llamar a las partes a conciliar, en los términos establecidos en la ley. Cualquier otra interpretación derivaría en que los artículos 263 y siguientes (es decir, todos menos el que establece el llamado propiamente tal) carecerían de valor y no producirían efecto alguno, cuestión que es repudiada por nuestro ordenamiento jurídico. Como regula el Código Civil, las normas deben ser interpretadas en armonía con el resto del cuerpo normativo en que se encuentran, lo que sirve para aclarar el sentido y alcance del artículo $795^{52}$.

\section{Prevención: las partes tienen el derecho a Conciliar Y NO LA OBLIGACIÓN DE HACERLO}

No quisiéramos dejar de hacernos cargo de una preocupación que ha tomado fuerza en relación con el poder que se otorga a los jueces en el manejo de las instancias conciliatorias, y concretamente, al nivel de presión que ejercen sobre las partes para lograr que lleguen a una conciliación. Este tema ha sido recurrente en el ámbito de la justicia laboral, donde la función conciliatoria de los jueces fue fortalecida con la dictación de la Ley No 20.260 el 2008, que estableció el nuevo procedimiento laboral ${ }^{53}$.

52 El artículo 22 del Código Civil, inciso primero, dispone que "[El] contexto de la ley servirá para ilustrar el sentido de cada una de sus partes, de manera que haya entre todas ellas la debida correspondencia y armonía", mientras que el artículo 24 del mismo cuerpo legal dispone que "[E]n los casos a que no pudieren aplicarse las reglas de interpretación precedentes, se interpretarán los pasajes obscuros o contradictorios del modo que más conforme parezca al espíritu general de la legislación y a la equidad natural”.

${ }^{53}$ Palomo, 2014, p. 383. 
En concreto, la crítica dice relación con el empoderamiento que se ha dado a los jueces mediante la figura de la inmediación, con el propósito de inyectar mayor celeridad a la tramitación de las causas ${ }^{54}$. Ese poder ha llevado a que los magistrados lleven sus labores a límites impensados, particularmente en materia conciliatoria, con el propósito de reducir su carga de trabajo ${ }^{55}$. Ello sin importar las vulneraciones a los derechos fundamentales de los litigantes, como la garantía del debido proceso en general y el derecho a la imparcialidad del juzgador en particular $^{56}$, las que han debido ser corregidas en diversas ocasiones por las Cortes de Apelaciones ${ }^{57}$.

La situación que se denuncia, que ha sido confirmada por estudios empíricos respecto de la materia ${ }^{58}$, es preocupante. Si bien se ha conseguido rebajar considerablemente el número de casos que terminan por sentencia (llegando el número de casos terminados por conciliación a $40 \%{ }^{59}$ ), el hecho de que ello haya sido producto de malas prácticas conciliatorias de los jueces - como presiones indebidas ${ }^{60}$, coerciones y amenazas ${ }^{61}$ - revela que no basta con fortalecer la figura de la conciliación y dejarla sobrevivir como mejor pueda. Es necesario un cambio cultural en los jueces, las partes y sus abogados. Así como señala Palomo, "la confianza depositada en los jueces debe ir siempre acompañada de límites explícitos que eviten que este mayor protagonismo judicial se traduzca en arbitrariedad, capricho o irracionalidad" 62 , sugiriendo luego que los abogados deben enfrentar estas instancias, y el poder del juez, con menos tolerancia y más reacción ${ }^{63}$.

Además, es necesario que todos los actores tengan presente que la conciliación es una alternativa a disposición de las partes, y no una imposición hacia ellas ${ }^{64}$. No hay que olvidar que esta figura es en esencia voluntaria. Por tanto el juez debe "proponer" bases de arreglo, no "imponer" bases de arreglo. Según hemos explicado, si esa propuesta es inteligente, fundada y expuesta de manera inteligente, sin duda que puede convencer a las partes de que es más atractiva que continuar litigando varios años más. Como lo sugieren Maturana y Rivero, "de lo que se trata es de poner a disposición de los ciudadanos vías de solución más adecuadas a la naturaleza y magnitud del conflicto que les afecta, más rápidas y desformalizadas, pero siempre con la posibilidad de acudir a un proceso civil que les permita satisfacer sus pretensiones con igual eficacia y rapidez" ${ }^{65}$.

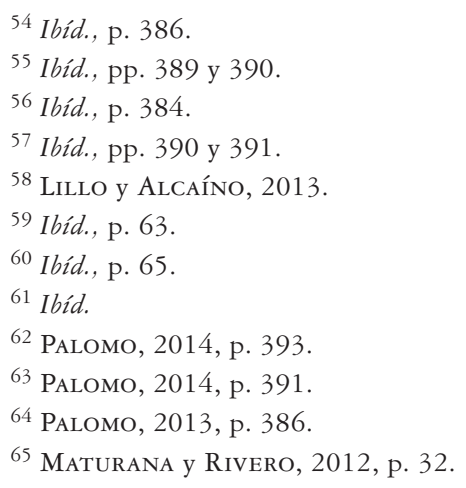


La experiencia en el proceso laboral debe ser tenida en cuenta al momento de fortalecer la conciliación en el proceso civil. Por un lado, porque es evidente el descenso que ha habido en el número de causas que llegan a sentencia definitiva, y ese es el objetivo que creemos debe perseguir los cambios que se implementen. Por otro lado es evidente que ese descenso en el número de causas no puede estar fundado en malas prácticas judiciales que fuerzan a las partes a arreglar, y en la debilidad de los abogados que no saben resguardar de manera adecuada los derechos de sus representados ¿Es posible que esa eficiencia para descongestionar los tribunales sea alcanzada con cabal respeto de los derechos de los litigantes? Creemos que sí. Así lo demuestra la experiencia de aquellas jurisdicciones que llevan varias décadas aprovechándose de los mecanismos alternativos de solución de controversias en general, y de la figura de la conciliación en particular.

\section{CONCLUSIÓN}

Diversas conclusiones se obtienen de lo expuesto en el presente trabajo. El punto de partida a todas ellas es el hecho innegable de que nuestro sistema procesal civil, como existe hoy, está obsoleto, y no sirve para dar respuesta eficiente a cada una de las causas que se promueven ante los tribunales.

En los últimos años han surgido diversas propuestas para corregir el sistema, siendo las más relevantes los dos proyectos de ley ingresados al Congreso para reformar por completo el procedimiento civil. Ambos proyectos no han avanzado de manera significativa. Es más, el primer proyecto (2009) fue reemplazado por el segundo (2012), y a esta fecha este último se encuentra descansando en las dependencias del Parlamento. Tan notoria es la demora en la reforma, que el 2015 entró en vigencia la ley sobre Tramitación Digital de los Procedimientos Judiciales, que vino a parchar, lo mejor que pudo, algunos de los arcaísmos e ineficiencias del proceso civil. El efecto práctico de esa ley es que vino a descomprimir una situación que ya era insostenible, restando por tanto urgencia a la reforma global que el proceso necesita.

Frente a lo anterior, no es mucho lo que se puede hacer para descongestionar los tribunales civiles de justicia. Los esfuerzos políticos hoy están centrados en otro tipo de asuntos, y es difícil que las autoridades quieran desgastarse, y distraer su tiempo, para algo que ya no es urgente.

En ese contexto la propuesta de fortalecer el trámite de la conciliación toma una gran relevancia. Según se expuso, hacerlo no requiere de la intervención del Poder Legislativo, y puede ser solucionado con la intervención exclusiva del Poder Judicial. Sus resultados por lo demás se encuentran probados, existiendo valiosa experiencia en el extranjero que demuestra que la solución alternativa de conflictos en general y la conciliación en particular es un eficiente mecanismo para alivianar la carga de trabajo de los tribunales civiles. Y si bien existen aprehensiones al respecto, particularmente por la experiencia vivida en las Cortes laborales del país, creemos que dichos problemas son perfectamente evitables si es que el fortalecimiento que proponemos es bien implementado, y todos los actores asumen y desempeñan correctamente el rol que les toca jugar. 


\section{BIBLIOGRAFÍA}

Aguirrezabal G., Maite (Editor), 2012, Justicia civil: Perspectivas para una reforma en la legislación chilena, Santiago: Universidad de los Andes, Cuadernos de Extensión Jurídica, No 23).

BoK, Derek, 1983, "A Flawed System of Law and Practice Training", Journal of Legal Education, volumen 33 .

Bordalí S., Andrés (2016), Derecho jurisdiccional, Valdivia: Ediciones Derecho Austral.

Centro de Estudios de Justicia de las Américas, 2011, Estudio de Análisis de Trayectoria de las Causas Civiles en los Tribunales Civiles de Santiago, Santiago. Disponible en http://rpc. minjusticia.gob.cl/media/2013/04/Estudio-Trayectorias-Causas-Civiles-en-TribunalesCiviles-Santiago.pdf. [Fecha de consulta: 23.02.2018].

Cappelletti, Mauro, 1999, Alternative Dispute Resolution Processes within the Framework of the World-Wide Access-to-Justice Movement, The Modern Law Review, volumen 56, № 3 .

Corral T., Hernán, 2013, Conciliación, avenimiento y transacción. Recuperado el 22.02.2018 de Derecho y Academia, el blog de Hernán Corral. Disponible en https://corraltalciani.wordpress. com/2013/05/19/conciliacion-avenimiento-y-transaccion/, [Fecha de consulta: 22.02.2018]

Galanter, Marc y Cahill, Mia, 1994, Most Cases Settle: Judicial Promotion and Regulation of Settlements, Stanford Law Review, volumen 46.

JEQUIER L., Eduardo, 2018, La mediación en asuntos civiles y comerciales y su vinculación con el proceso civil en Chile. Estudio de lege farenda a partir de los resultados de encuestas dirigidas a abogados, jueces y empresarios chilenos (junio-julio de 2016) en VÁsquez P., María Fernanda (Dir.), 2018, Mecanismos Alternativos de Solución de Conflictos. Estado actual, problemas existentes y propuestas de solución, Santiago: Ed. Thomson Reuters.

Larroucau T., Jorge, 2017, Adiós a las fojas. Reglas procesales, autos acordados y tramitación electrónica en Chile, Revista de Derecho Privado, Vol. 33, pp. 195 a 234. Disponible en http:// www.scielo.org.co/scielo.php?script =sci_abstract\&pid =S0123-43662017000200195\&lng $=$ en\&nrm $=$ iso\&tlng $=$ es. [Fecha de consulta: 15.01.2019].

Lillo, Ricardo y Alcaíno, Eduardo (Centro de Estudios de la Justicia de las Américas), 2013, Reporte sobre el funcionamiento a la reforma a la Justicia laboral en Chile. Disponible en http:// biblioteca.cejamericas.org/bitstream/handle/2015/1224/ReportesobreelFuncionamiento_ ReformaJusticiaLaboralenChile.pdf? sequence =1\&isAllowed $=y$, [Fecha de consulta: 23.02.2018].

Luban, David, 1995, Settlements and the Erosion of the Public Realm, Georgetown Law Journal, volumen 83 .

NúÑez O., Raúl y Larroucau T., Jorge, 2018, La conciliación en los procedimientos civiles, en VÁsquez P., María Fernanda (Dir.), 2018, Mecanismos Alternativos de Solución de Conflictos. Estado actual, problemas existentes y propuestas de solución, Santiago: Ed. Thomson Reuters.

Maturana M., Cristián y Rivero H., Renée, 2012, Un Nuevo Sistema Procesal Civil: Una Necesidad Social Impostergable o un Antojo Meramente Académico, en Aguirrezabal G., Maite (Editor): 2012, Justicia civil: Perspectivas para una reforma en la legislación chilena, Universidad de los Andes, Cuadernos de Extensión Jurídica, volumen 23.

Palomo V., Diego y Matamala S., Pedro, 2012, Los problemas de los poderes ex officio del juez laboral. Ahora a propósito de la potestad conciliatoria, Revista Ius et Praxis, año 18, $\mathrm{N}^{\circ} 1$, pp. 439-456. Disponible en https://scielo.conicyt.cl/scielo.php?script=sci_arttext\&pid =S0718-00122012000100015. [Fecha de consulta: 15.01.2019].

Palomo V., Diego, 2013, Algunos apuntes a contracorriente sobre la jurisdicción, los mecanismos alternativos de resolución de conflictos, los equivalentes jurisdiccionales y en especial la mediación en materia de salud, en Arancibia M., Jaime; Martínez E., José Ignacio; y Romero S., Alejandro 
(Eds.), 2013, Precedente, Cosa Juzgada y Equivalentes Jurisdiccionales en la Litigación Pública, Thomson Reuters-Legal Publishing.

Palomo V., Diego, 2014, Sobre la conducta procesal de algunos jueces. De vuelta con la unidimensionalidad de la eficiencia y la potestad conciliatoria como excusas, Revista Ius et Praxis, año 20, $\mathrm{N}^{\circ} 1$, pp. 377-396. Disponible en https://scielo.conicyt.cl/scielo.php?script=sci_arttext\&pid =S0718-00122014000100016. [Fecha de consulta: 23.02.2018].

Roberts, Simon, y PALmer, Michael, 2005, Dispute processes: ADR and the primary forms of decisionmaking (2 Ed), Cambridge: Cambridge University Press.

Romero S., Alejandro, 2013, ¿Ejecución Provisional sin Caución? (el Proceso y los Dados), en Aguirrezabal G., Maite (Editor): 2012, Justicia civil: Perspectivas para una reforma en la legislación chilena, Universidad de los Andes, Cuadernos de Extensión Jurídica, volumen 23.

TAPIA A., Hugo, 1944, Las Reformas introducidas en el Libro I del C. de Procedimiento Civil por la Ley 7760, Revista de Derecho Universidad de Concepción, volumen 50.

Woolf, Harry, 1995, Access to Justice: Interim Report to the Lord Chancellor on the Civil Justice System of England and Wales. Disponible en http://webarchive.nationalarchives.gov.uk/+/http:// www.dca.gov.uk/civil/final/contents.htm. [Fecha de consulta: 22.02.2018].

Zuckerman, Adrian, 2013, Zuckerman on Civil Procedure, Principles of Practice", $3^{\mathrm{a}}$ Ed., Londres: Sweet \& Maxwel. 